\title{
BMJ Global Health Child mortality associated with maternal HIV status: a retrospective analysis in Rwanda, 2005-2015
}

Eric Remera (10 , ${ }^{1,2,3,4,5}$ Frédérique Chammartin, ${ }^{3,4}$ Sabin Nsanzimana, ${ }^{1,5}$ Jamie Ian Forrest, ${ }^{6}$ Gerald E Smith, ${ }^{7}$ Placidie Mugwaneza, ${ }^{1}$ Samuel S Malamba, ${ }^{8}$ Muhammed Semakula, ${ }^{1,9,10}$ Jeanine U Condo, ${ }^{11,12}$ Nathan Ford, ${ }^{13}$ David J Riedel, ${ }^{14}$ Marie Paul Nisingizwe, ${ }^{6}$ Agnes Binagwaho, ${ }^{5}$ Edward J Mills (D) ,7,15 Heiner Bucher, ${ }^{3,4}$

To cite: Remera E,

Chammartin F, Nsanzimana S, et al. Child mortality associated with maternal HIV status: a retrospective analysis in Rwanda, 20052015. BMJ Global Health 2021;6:e004398. doi:10.1136/ bmjgh-2020-004398

Handling editor Sanni Yaya

Received 5 November 2020 Revised 22 January 2021 Accepted 26 January 2021

Check for updates

C Author(s) (or their employer(s)) 2021. Re-use permitted under CC BY-NC. No commercial re-use. See rights and permissions. Published by BMJ.

For numbered affiliations see end of article.

Correspondence to

Eric Remera;

ericremera@gmail.com

\section{ABSTRACT}

Introduction Child mortality remains highest in regions of the world most affected by HIV/AIDS. The aim of this study was to assess child mortality rates in relation to maternal HIV status from 2005 to 2015, the period of rapid HIV treatment scale-up in Rwanda.

Methods We used data from the 2005, 2010 and 2015 Rwanda Demographic Health Surveys to derive under-2 mortality rates by survey year and mother's HIV status and to build a multivariable logistic regression model to establish the association of independent predictors of under-2 mortality stratified by mother's HIV status. Results In total, 12010 live births were reported by mothers in the study period. Our findings show a higher mortality among children born to mothers with HIV compared with HIV negative mothers in 2005 (216.9 vs 100.7 per 1000 live births) and a significant reduction in mortality for both groups in 2015 (72.0 and 42.4 per 1000 live births, respectively). In the pooled reduced multivariable model, the odds of child mortality was higher among children born to mothers with HIV, (adjusted OR, AOR 2.09; 95\% Cl 1.57 to 2.78). The odds of child mortality were reduced in 2010 (AOR $0.69 ; 95 \% \mathrm{Cl} 0.59$ to 0.81 ) and 2015 (AOR $0.35 ; 95 \% \mathrm{Cl}$ 0.28 to 0.44 ) compared with 2005. Other independent predictors of under-2 mortality included living in smaller families of 1-2 members (AOR $5.25 ; 95 \% \mathrm{Cl} 3.59$ to 7.68), being twin (AOR 4.93; 95\% $\mathrm{Cl} 3.51$ to 6.92 ) and being offspring from mothers not using contraceptives at the time of the survey (AOR 1.6; $95 \% \mathrm{Cl} 1.38$ to 1.99). Higher education of mothers (completed primary school: (AOR $0.74 ; 95 \% \mathrm{Cl} 0.64$ to 0.87 ) and secondary or higher education: (AOR $0.53 ; 95 \% \mathrm{Cl} 0.38$ to 0.74 )) was also associated with reduced child mortality.

Conclusions This study shows an important decline in under-2 child mortality among children born to both mothers with and without HIV in Rwanda over a 10-year span.

\section{INTRODUCTION}

Of the approximately 37.9 million individuals living with HIV in 2018, the majority resided in sub-Saharan Africa including approximately 1.7 million children under 15 years of

\section{Key questions}

What is already known?

- Previously, children's mortality was assessed regardless of the mothers' HIV status.

- The survival of children born to mothers with HIV was typically worse than those children born to mothers without HIV

- The antiretroviral treatment scale-up among pregnant women has considerably reduced the vertical transmission of HIV.

\section{What are the new findings?}

- This study determines the impact of treatment scaleup and the option B+ programme on child mortality, which has not yet been evaluated in Rwanda.

- This manuscript investigates the association between maternal HIV status and childhood mortality over time as HIV treatment scale-up was occurring in the country.

- Using Demographic Health Surveys from three time points ranging from just before rapid antiretroviral therapy scale-up to after implementation of 'option $\mathrm{B}+$ ', this analysis compares the decline in under-2 mortality among children born of both mothers with and without HIV.

\section{What do the new findings imply?}

- Further biomedical interventions are needed to achieve the Sustainable Development Goals.

- More studies are recommended to monitor the encouraging decline in child mortality and test emerging interventions.

age. ${ }^{12} \mathrm{HIV} /$ AIDS is a major cause of mortality among children under 5 years of age. ${ }^{3}$ Globally, remarkable gains in reducing child mortality in the previous decades have decreased mortality from 93 to 39 deaths per 1000 live births between 2000 and 2018. ${ }^{4}$ However, important regional differences contributed to these gains. Sub-Saharan Africa (57\% decline), for instance, had a slower decline compared with Northern Africa and Western 
Asia (65\% reduction), Central and Southern Asia (68\% reduction), Eastern and South-Eastern Asia (74\% reduction), Latin America and the Caribbean (70\% reduction) and Europe and Northern America (60\% reduction). ${ }^{4}$ As of 2018, sub-Saharan Africa continues to rank as the region of the world with the highest child mortality of 78 deaths per 1000 live births. ${ }^{5}$ While the United Nation's Sustainable Development Goals target to reduce under-5 mortality to less than 25 per 1000 live births by 2030 in all countries, a global review of national mortality trends showed that efficient control of HIV/AIDS would decrease the under-five mortality rate by $14 \%$ per decade from 2010 to $2030 .{ }^{6}$

A number of factors have been identified as associated with higher child mortality in sub-Saharan Africa. These include low coverage of vaccination, poor hygiene and sanitation, inadequate nutrition and maternal socioeconomic and HIV status. ${ }^{5-10}$ Many countries in the region, including Eritrea, Ethiopia, Liberia, Malawi, Mozambique, Niger, Rwanda, Uganda and Tanzania observed a reduction in the under-five mortality rate between 1990 and 2018 by up to two-thirds. Substantial gains in reducing child mortality have been made in Rwanda since the scale-up of HIV and other primary health services over the last decade, resulting in the country being one of the few to meet Millennium Development Goal (MDG) $-4 .^{5}$

In Rwanda, many efforts have been made over the past two decades to reduce mother-to-child HIV transmission as part of the country's efforts to reduce child mortality. ${ }^{11}$ In 2012, all pregnant women with HIV were enrolled into the 'option B+ programme' that provides lifelong antiretroviral therapy (ART), irrespective of a mother's CD4-cell count, ${ }^{12}$ as well as a close follow-up of mothers and their children until 24 months postdelivery. By June 2019, 98\% of health facilities countrywide provided Prevention of Mother to Child Transmission (PMTCT) services. This resulted in $99 \%$ of pregnant women with HIV attending at least one antenatal care visit, $86 \%$ being accompanied by their partners for HIV testing and $91 \%$ delivering in a health facility with the assistance of a skilled healthcare provider. ${ }^{13}$ The survival of children of mothers with HIV has been investigated in Rwanda using cohort studies for shorter durations of follow-up, ${ }^{11} 1415$ yet these analyses were not based on data available from nationally representative population surveys. Furthermore, the impact of nationwide HIV treatment scale-up on child mortality has not yet been evaluated in Rwanda. In this study, we assess child mortality among children less than 2 years of age born to mothers with and without HIV using populationbased survey data (Rwanda Demographic and Health Survey, RDHS) from 2005 to 2015, corresponding to the timeframe of massive HIV treatment scale-up in Rwanda.

\section{METHODS \\ Study design}

The RDHS is a standardised cross-sectional household survey conducted every 5 years. RDHS uses a two-stage cluster sampling procedure that aims to guarantee a representative sample of the target population. The sampling frame was generated first by a random sample of villages, followed by a second stage of random sampling of households within each of these villages. Sampling of each year's RDHS is done independently from each other and there is little chance that a household is part of two or more RDHS, given the low selection probability of a cluster. The survey collects data about adult males 15-54 and females $15-49$ years of age. ${ }^{16}$

\section{Public involvement}

The RDHS is implemented by the National Institute of Statistics of Rwanda and the Ministry of Health of Rwanda under the technical assistance of Inner City Fund (ICF) International through the DHS Programme. Together with other stakeholders, the Ministry of Local Government participates in the design, implementation and dissemination of the study. Specifically, local authorities play a key role during the data collection to ensure the smooth implementation in their respective areas.

\section{Data}

We used data from RDHS from 2005, 2010 and 2014/2015 on children born in the 5years prior respective surveys administration from all mothers tested for HIV. During each survey, every woman sampled was interviewed about her maternal history and the vital status of her children at the time of the survey. RDHS obtained informed consent for interviews from all participants and for blood draws for HIV testing of all mothers. RDHS sampled 50\% of interviewed mothers for HIV testing. The response rate was $98.1 \%$ in $2005,99,1 \%$ in 2010 and $99.5 \%$ in 2015 and the HIV test consent rate was $97.0 \%$ in $2005,98.9 \%$ in 2010 and $99.5 \%$ in 2015 . We included all children from sampled mothers tested for HIV under the age of 2years born 24-84 months preceding the survey, excluding the month of the interview. Therefore, a cohort of children who were deemed to reach the age of 2 years in the 5 years prior to the survey was considered for analysis of under-2 mortality, defined as death between birth and 23 months of age. Deaths were solely based on the report of the mothers.

In total 92769 children were born to sampled mothers (30072 in 2005, 32639 in 2010 and 30058 in 2015, respectively) and 23587 were born within an interval of 24 and 84 months prior to each survey (RDHS 2005, 2010 and 2014/2015). Of them, 11816 children were born to mothers, who were offered an HIV test. Our study population was constituted with 3627 mothers from the RDHS 2005, 4381 mothers from the RDHS 2010, and 3808 mothers from the RDHS 2015 (figure 1).

\section{Under-2 mortality predictors}

Following a literature review and the development of a conceptual framework we identified the following available variables as potential predictors of under-2 mortality: the mother's HIV and marital status at the time of the survey, the mother's education level (no education, primary, 


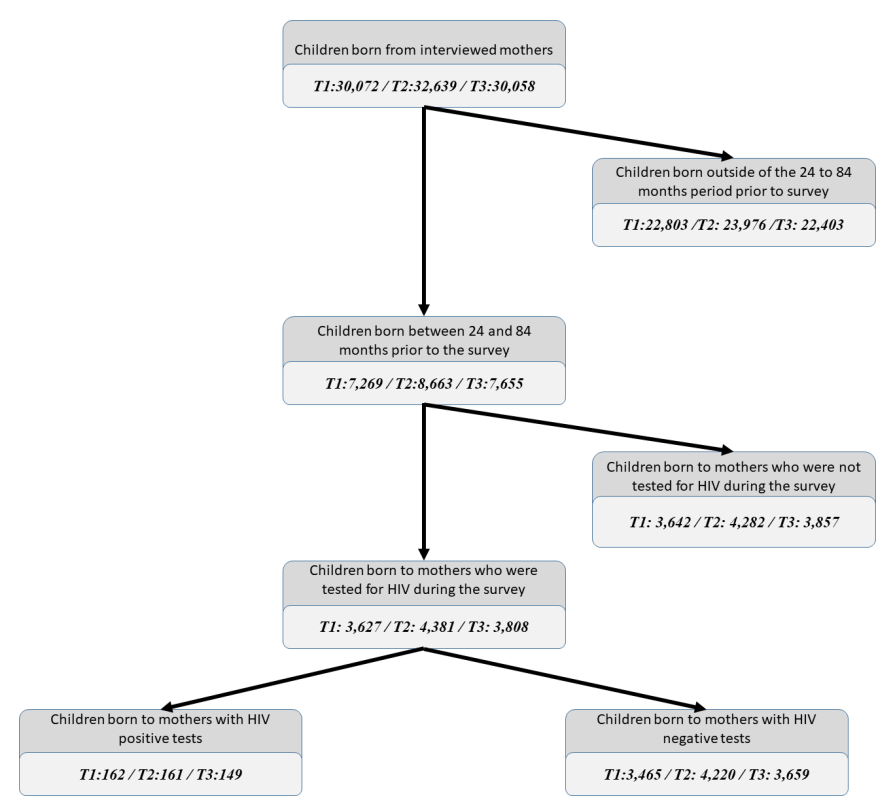

Figure 1 Recruitment flow.

secondary/higher) and age at childbirth $(<25,25-34,35+$ yearsold), residence type (urban/rural), mother's occupation (not working; skilled work (professional, clerical, sales, services, skilled manual)); unskilled work: (agriculture, domestic, unskilled manual), size of the family (1-2, 3-4, 5+ members), use of modern contraceptives (contraceptive pill, intrauterine device, injectable, male condom and implants, female sterilisation) at the time of the survey, preceding birth spacing (first born, less than 24 months, 25-36 months, $37-48$ months and 49 plus months), twin birth (yes/no), source of drinking water (categorised as 'improved' if the source is piped water into dwelling/yard/plot, public tap/ standpipe, borehole, protected dug well, protected spring, rainwater, bottled water) as a socioeconomic proxy, and the availability of treated bed nets in the household (yes/no).

\section{Statistical analysis}

Mortality rates were calculated for each RDHS period using a self-modified version of the 'chmort' function from the R statistical package 'DHS.rates', used to calculate under five mortality, to allow calculation of under-2 child mortality. ${ }^{17}$

Multivariable logistic regression models were constructed for each RDHS period with the aforementioned variables identified as potential predictors of under-2 mortality. Variables that were significantly associated $(p<0.05)$ were considered as important predictors and were carried forward to develop a final reduced multivariable logistic model on the pooled data over the three RDHS periods in order to quantify the effect of the calendar period on the risk of under-2 childhood mortality. Logistic regression models were constructed with Stata V.15 software $^{18}$ using 'svy' commands accounting for sample weights.

RDHS data were used for this study.

\section{RESULTS}

In total, the sample consisted of 12010 mothers tested for HIV during the three RDHS in 2005, 2010 and 2015. Of these, 450 (3.7\%) were HIV positive. Most of the tested mothers were in marital unions at the time of the surveys $(85.3 \%)$, had primary or higher education $(78.5 \%)$, lived in a rural area $(86.2 \%)$, lived in households with an improved source of drinking water $(73.8 \%)$ and did not use contraceptives at the time of the surveys $(63.5 \%)$. Roughly, half of them gave birth between ages 25 and 34 years $(48.8 \%)$, lived in families of more than five members $(47.7 \%)$ and were poor $(43.4 \%)$. With the exception of primary or higher education which increased from $70.3 \%$ in 2005 to $82.8 \%$ in 2015 and availability of bed nets at household, which increased from $17.4 \%$ in 2005 to $72.3 \%$ in 2015 the characteristics of mothers who tested positive for HIV were stable across the RDHS periods (table 1).

Under-2 mortality per 1000 live births in 2005 was higher among children born to mothers with HIV compared with HIV negative mothers (216.9; $95 \%$ CI 144.5 to 289.3 versus $100.7 ; 95 \%$ CI 88.8 to 112.7$)$. In 2010 , the respective mortality rates were 131.4 (95\% CI 79.8 to 182.9 ) among children born to mothers with HIV versus 66.7 (95\% CI 58.7 to 74.7$)$ per 1000 live births among children born to HIV negative mothers. In 2015, mortality rates were 72.0 (95\% CI 31.2 to 111.9 ) versus 42.4 (95\% CI 35.5 to 49.4 ) per 1000 live births born to mothers with HIV and HIV negative mothers, respectively (table 2 ).

Results from the logistic regression models are presented in table 3 . The odds of dying for children born to mothers with HIV increased from 1.93; $95 \%$ CI 1.16 to 3.22 in 2005 to $2.66 ; 95 \%$ CI 1.72 to 4.14 in 2010. The multivariable model shows that children born from mothers with HIV were at higher risk of dying before age 2 years compared with children born from HIV negative mothers (adjusted OR (AOR) 2.09; $95 \%$ CI 1.57 to 2.78$)$ ). The risk of dying before age 2 was reduced by $31 \%$ in 2010 compared with 2005 (AOR $0.69 ; 95 \%$ CI 0.59 to 0.81 ) and by $65 \%$ in 2015 compared with 2005 (AOR $0.35 ; 95 \%$ CI 0.28 to 0.44 ). Other independent predictors of under- 2 mortality included living in smaller families of 1-2 members (AOR 5.25; 95\% CI 3.59 to 7.68), being a twin (AOR $4.93 ; 95 \%$ CI 3.51 to 6.92 ), living in a rural area (AOR $1.47 ; 95 \%$ CI 1.18 to 1.84 ) and being an offspring from mothers not using contraceptives at the time of the survey (AOR 1.66; 95\% CI 1.38 to 1.99). Being a child from mothers with completed primary school was preventative (AOR 0.74; 95\% CI 0.64 to 0.87 ) and secondary or higher education (AOR $0.54 ; 95 \% \mathrm{CI}$ 0.38 to 0.75 ) as well as increased preceding birth spacing, compared with children who were born less than 24 months after their siblings, of 25-36 months (AOR 0.55; 95\% CI 0.45 to 0.66), 37-48 months (AOR $0.50 ; 95 \%$ CI 0.39 to 0.64 ), above 49 months (AOR 
Table 1 Characteristics of mothers tested for HIV in 2005, 2010 and 2015

2005

2010

2015

Total

n (weighted) Per cent $\mathbf{n}$ (weighted) Per cent $\mathbf{n}$ (weighted) Per cent $\mathbf{n}$ (weighted) Per cent

Overall 3659 4443 3908 12010

\section{Mother's HIV test results}

$\begin{array}{lrrrrrrrr}\text { HIV negative } & 3517 & 96.1 & 4283 & 96.4 & 3759 & 96.2 & 11560 & 96.3 \\ \text { HIV positive } & 141 & 3.9 & 160 & 3.6 & 148 & 3.8 & 450 & 3.7 \\ \begin{array}{l}\text { Current marital status } \\ \text { Not in union }\end{array} & 516 & 14.1 & 592 & 13.3 & 654 & 16.7 & 1762 & 14.7 \\ \text { In union } & 3143 & 85.9 & 3851 & 86.7 & 3254 & 83.3 & 10248 & 85.3\end{array}$

\section{Highest educational level}

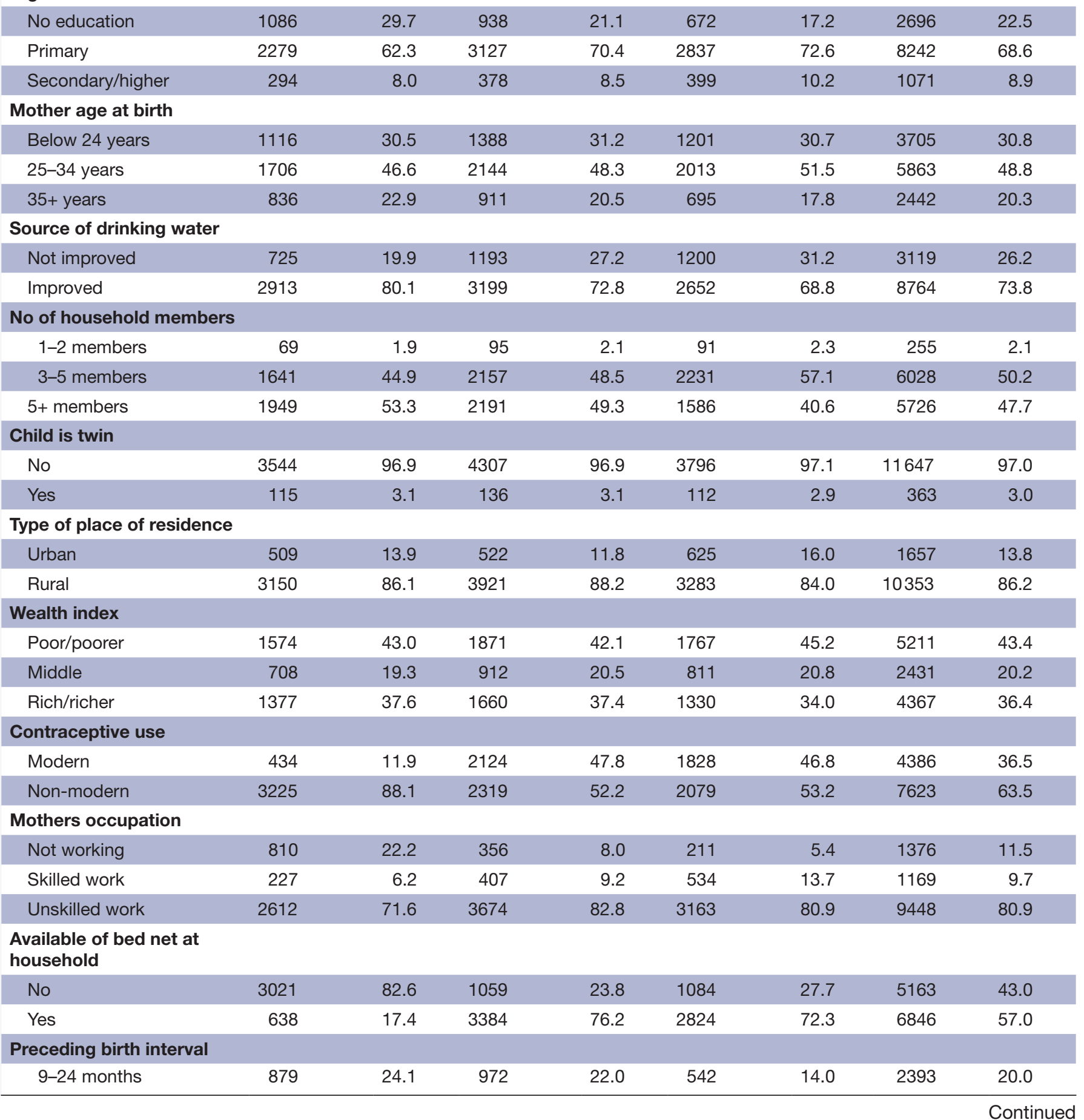




\begin{tabular}{|c|c|c|c|c|c|c|c|c|}
\hline & \multicolumn{2}{|l|}{2005} & \multicolumn{2}{|l|}{2010} & \multicolumn{2}{|l|}{2015} & \multicolumn{2}{|l|}{ Total } \\
\hline & n (weighted) & Per cent & n (weighted) & Per cent & n (weighted) & Per cent & n (weighted) & Per cent \\
\hline 25-36 months & 1133 & 31.0 & 1330 & 30.1 & 888 & 22.9 & 3351 & 28.0 \\
\hline $37-48$ months & 553 & 15.1 & 638 & 14.4 & 548 & 14.1 & 1739 & 14.5 \\
\hline $49+$ months & 457 & 12.5 & 501 & 11.3 & 772 & 19.9 & 1731 & 14.5 \\
\hline First born & 628 & 17.2 & 983 & 22.2 & 1133 & 29.2 & 2745 & 23.0 \\
\hline
\end{tabular}

$0.43 ; 95 \%$ CI 0.33 to 0.55 ) and the first born (AOR $0.73 ; 95 \%$ CI 0.59 to 0.91 ) (table 3 ).

\section{DISCUSSION}

In this comparative study of nationwide representative health survey data from 2005 (the first DHS to collect HIV biomarker) to 2015, we demonstrated a marked decline in under-2 child mortality among children born of both mothers with and without HIV. The decrease in the under-2 childhood mortality was more pronounced in children born from mothers with HIV, and children born to mothers with and without HIV had a similar mortality by 2015. Despite the widespread scale up of HIV services starting in 2004, data show a higher odds of dying before the age of two among children born from mothers with HIV compared to those with no HIV in 2010. This near normalisation of childhood mortality for children born to mothers with HIV compared with those without HIV seen in 2015 likely reflects the vast gains in HIV care and mother-to-child HIV transmission experienced in Rwanda over the last decade. Children born in small households, of one to two members (most probably from single mothers), as well as from mothers with lower education, in rural areas, and those born twins were predictive of a higher risk of mortality. The family size includes the nuclear family members and dependents residing in the same household. Other studies in resource-limited settings have revealed that single motherhood, unwanted pregnancy and lack of spousal support are a higher risk of child mortality. However, this risk may also be attributed to emotional violence and the lack of economical support. ${ }^{19} 20$

Several factors contributed to the decline of childhood mortality under 5 years of age in Rwanda as outlined in a recent review. ${ }^{21}$ These factors include the establishment of community health workers, a premium-based

Table 2 Under-2 mortality rates from 2005 to 2015 in Rwanda, by HIV mother status

\begin{tabular}{lcc}
\hline \multirow{2}{*}{$\begin{array}{l}\text { Survey } \\
\text { period }\end{array}$} & \multicolumn{2}{c}{ Under-2 mortality $\mathbf{( 9 5 \%} \mathbf{C l})$ (per $\mathbf{1 0 0 0}$ births) } \\
\cline { 2 - 3 } & HIV negative mothers & HIV positive mothers \\
\hline 2005 & $100.7(88.8$ to 112.7$)$ & $216.9(144.5$ to 289.3$)$ \\
\hline 2010 & $66.7(58.7$ to 74.7$)$ & $131.4(79.8$ to 182.9$)$ \\
2015 & $42.4(35.5$ to 49.4$)$ & $72.0(31.2$ to 111.9$)$ \\
\hline
\end{tabular}

community health insurance (Mutuelle de Santé), the scale up of contraceptive use, the decentralisation and integration of health services, increased domestic funding for health and the scale up of a national HIV PMTCT programme. $^{22} 23$ By 2011, 22.1\% of general government expenditures were allocated to the public health sector. As a result, rates of child and maternal mortality, and deaths due to tuberculosis and malaria have fallen alongside the burden of HIV, and Rwanda is now on track for each of the health-related MDGs. ${ }^{21}$ Other factors contributing to these trends are the country's engagement in initiatives to obtain gender parity and equal access to education. $^{24}$

In addition to interventions that reduce mortality among all children, interventions to reduce disparities among children born of HIV positive mothers, compared with negative mothers have also been scaled up in Rwanda. Most notably, in 2005, only $5.5 \%$ of persons living with HIV were taking HIV treatment compared with $81.2 \%$ in $2015 .{ }^{25}$ During the same period, access to PMTCT services more than doubled; from $41.3 \%$ in 2005 to $85.1 \%$ in $2015 .^{25}$ Similarly, infant delivery at a health facility has steadily increased from $28 \%$ in 2005 to $91 \%$ in $2015 .^{26}$ The difference in childhood mortality in 2010 and 2005 concurs with findings of a study that was conducted in sub-Saharan Africa when PMTCT and ART programme was not yet scaled up. ${ }^{27}$ In addition, a study conducted in South Africa has reported a decline in under-2 mortality as a result of HIV prevention and treatment, ${ }^{28}$ and different studies conducted in Africa highlighted equal chances of child survival as result of maternal HIV treatment. ${ }^{29}$ Higher education and access to modern contraceptive methods was also found in many other studies to be associated with reduced child mortality. ${ }^{10} 30-34$

Our study has several limitations: First, the analysis is based on cross-sectional survey data and, the HIV status of the mother and the child was not determined at the time of delivery or during the follow-up because data were collected during surveys and time of infection could not be determined. Second, the design of the study also precludes the determination of the HIV status of children, and hence whether or not the child's death was directly attributable to HIV remained undetermined. The latter may be a source of bias, however, as no available data on a child's HIV status, we had to make the best use of available data. Third, mothers with 


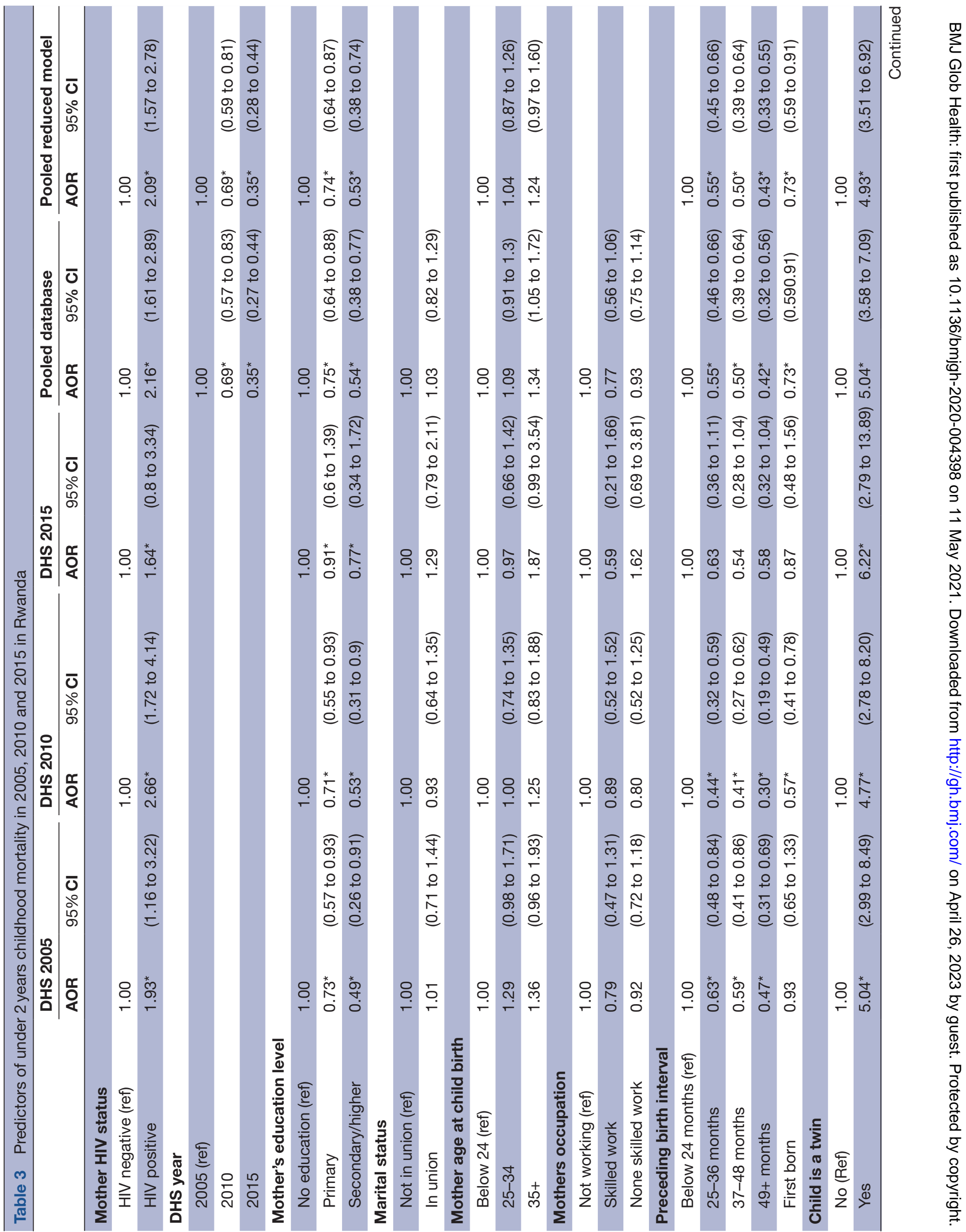




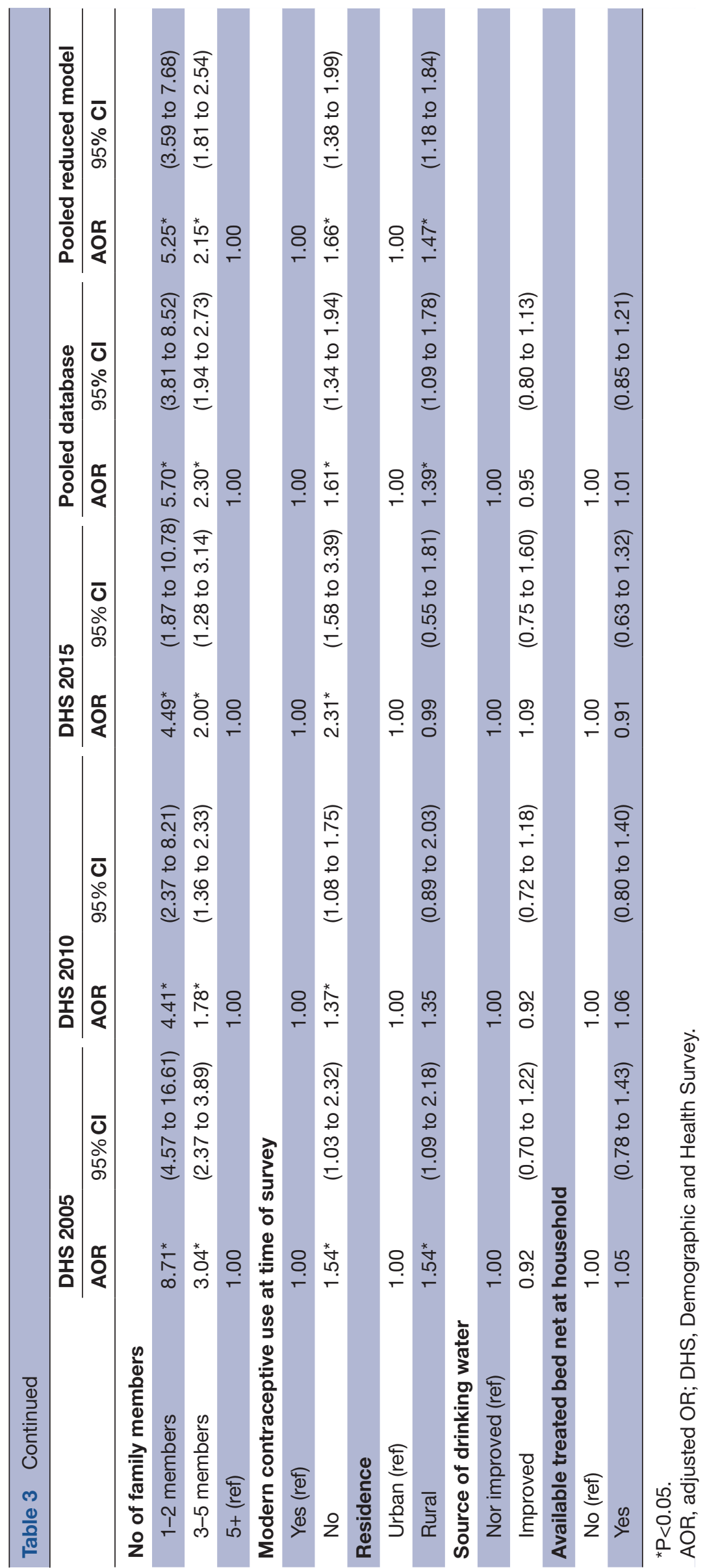

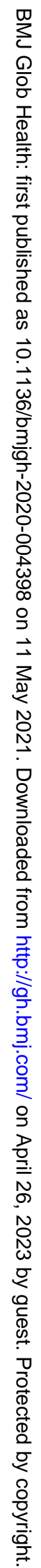


HIV who had died between the time of the health survey but had given birth within the retrospective time window for assessing childhood mortality are not represented in this analysis and the life status of their children is unknown; however, we estimate that this might be lower given the high ART coverage and increase in life expectancy among PLHIV on ART in Rwanda. ${ }^{35}$ Fourth, infant death was self-reported and not able to be verified by national mortality statistics. However, it is very unlikely that reporting of mothers might be differential to HIV status of the mother, thereby limiting the impact of any potential recall bias. Fifth, the cause of deaths for child mortality and impact PMTCT programmes cannot be directly assessed from this data. Finally, there are factors other than HIV treatment scale-up, which likely contributed to the reduction in child mortality, such as other improvements in maternal-child health interventions or general socioeconomic growth in the country.

\section{CONCLUSION}

This study shows a large reduction of childhood mortality between 2005 and 2015 in Rwanda. By 2015 the former considerable discrepancy in mortality of children less than 2 years of age and born to mothers with HIV has disappeared and now resembles rates of progeny from HIV negative mothers. Substantial gains have been made in Rwanda to scale-up health services and, maternal and child health programmes that include family planning and vaccination, ART and to improve the health system. However, more biomedical interventions related to empowering women, improving their education and economic status, and increasing the uptake of family planning services are needed to achieve the strategic development goal of reducing under-five mortality to less than 25 per 1000 live birth. As the health system is maturing in Rwanda, more studies are recommended to monitor these encouraging decline in child mortality and test emerging interventions.
${ }^{15}$ Department of Health Research Methods, Evidence, and Impact, McMaster University, Hamilton, Ontario, Canada

Twitter Eric Remera @eRemera and Sabin Nsanzimana @nsanzimanasabin

Acknowledgements The authors acknowledge the support and contributions of the Rwandan Ministry of Health, Rwanda Biomedical Centre, Basel Institute for Clinical Epidemiology and Biostatistics Department of Clinical Research, University Hospital Basel, Switzerland, MTEK Sciences, National Institute of Statistics of Rwanda and ICF Macro.

Contributors ER, SN, JIF, FSC, PM, SSM, AB, NF, DJR and HB contributed to study concept and design. ER, FSC, PM, NF, HB and DJR contributed to draft the manuscript. ER, NF, DJR, PM, SSM, JIF, JUC, SN, HB and AB contributed to acquisition. All authors contributed to interpretation of data and critical revision of the manuscript for important intellectual content; ER, SSM, MPN, SSM, FSC and GES contributed to statistical analysis, and AB, EJM and HB supervised the study. All authors have read and approved the final manuscript.

Funding The authors have not declared a specific grant for this research from any funding agency in the public, commercial or not-for-profit sectors.

Competing interests None declared.

Patient and public involvement Patients and/or the public were involved in the design, or conduct, or reporting, or dissemination plans of this research. Refer to the Methods section for further details.

Patient consent for publication Not required.

Ethics approval The protocols for RDHS in Rwanda were reviewed and approved by the Rwanda National Ethics Committee, the Institutional Review Board of ICF International, and the Centers for Disease Control and Prevention (CDC) in Atlanta

Provenance and peer review Not commissioned; externally peer reviewed.

Data availability statement Data are available in a public, open access repository. Data used in this analysis was retrieved from open online source the Rwanda DHS 2005, 2010 and 2014-2015. These data are freely available upon request at MEASURE DHS website https://dhsprogram.com/data/availabledatasets.cfm. The merged datasets used in this manuscript are available on request to the corresponding author.

Open access This is an open access article distributed in accordance with the Creative Commons Attribution Non Commercial (CC BY-NC 4.0) license, which permits others to distribute, remix, adapt, build upon this work non-commercially, and license their derivative works on different terms, provided the original work is properly cited, appropriate credit is given, any changes made indicated, and the use is non-commercial. See: http://creativecommons.org/licenses/by-nc/4.0/.

\section{ORCID iDs}

Eric Remera http://orcid.org/0000-0002-6084-8877

Edward J Mills http://orcid.org/0000-0003-3120-9694

\section{REFERENCES}

1 UNAIDS. UNAIDS. Global HIV \& AIDS statistics fact sheet, 2019. Available: https://www.unaids.org/en/resources/fact-sheet

2 Kharsany ABM, Karim QA. Hiv infection and AIDS in sub-Saharan Africa: current status, challenges and opportunities. Open AIDS J 2016;10:34-48.

3 Lane CE, Bobrow EA, Ndatimana D, et al. Determinants of growth in HIV-exposed and HIV-uninfected infants in the Kabeho study. Matern Child Nutr 2019;15:e12776.

4 UNICEF: WHO: World Bank: UN DESA. Levels \& Trends in Child Mortality 2019, 2019: 52 .

5 Amoroso CL, Nisingizwe MP, Rouleau D, et al. Next wave of interventions to reduce under-five mortality in Rwanda: a crosssectional analysis of demographic and health survey data. BMC Pediatr 2018;18:27.

6 Norheim OF, Jha P, Admasu $\mathrm{K}$, et al. Avoiding $40 \%$ of the premature deaths in each country, 2010-30: review of national mortality trends to help quantify the UN sustainable development goal for health. Lancet 2015;385:239-52.

7 Chihana ML, Price A, Floyd S, et al. Maternal HIV status associated with under-five mortality in rural Northern Malawi: a prospective cohort study. J Acquir Immune Defic Syndr 2015;68:81-90.

8 Yaya S, Bishwajit G, Okonofua F, et al. Under five mortality patterns and associated maternal risk factors in sub-Saharan Africa: a multicountry analysis. PLoS One 2018;13:e0205977. 
9 Ezeh OK, Agho KE, Dibley MJ, et al. Risk factors for postneonatal, infant, child and under-5 mortality in Nigeria: a pooled crosssectional analysis. BMJ Open 2015;5:e006779.

10 Ayele DG, Zewotir TT. Comparison of under-five mortality for 2000 , 2005 and 2011 surveys in Ethiopia. BMC Public Health 2016;16:930

11 Gill MM, Hoffman HJ, Ndatimana D, et al. 24-Month HIV-free survival among infants born to HIV-positive women enrolled in option B+ program in Kigali, Rwanda: the Kabeho study. Medicine 2017;96:e9445.

12 Ministry of Health (Rwanda). National guidelines for prevention and management of HIV and STIs. Kigali, Rwanda, 2016.

13 Rwanda Ministry of Health. National HIV and viral hepatitis annual report, 2018.

14 Mugwaneza P, Lyambabaje A, Umubyeyi A, et al. Impact of maternal art on mother-to-child transmission (MTCT) of HIV at six weeks postpartum in Rwanda. BMC Public Health 2018;18:1248.

15 Peltier CA, Ndayisaba GF, Lepage P, et al. Breastfeeding with maternal antiretroviral therapy or formula feeding to prevent HIV postnatal mother-to-child transmission in Rwanda. AIDS 2009;23:2415-23.

16 ICF International. Demographic and health survey sampling and household listing manual. ICF Int, 2012: 1-98.

17 Elkasabi M. Calculating fertility and childhood mortality rates from survey data using the DHS.rates R package. PLoS One 2019;14:e0216403.

18 College Station TSL. StataCorp 15. Release: Stata Statistical Software, 2017.

19 Clark S, Hamplová D. Single Motherhood and Child Mortality in SubSaharan Africa : A Life Course Perspective 2013:1521-49.

20 Bawah AA, Asuming PO, Debpuur C, et al. Child wanted and when? fertility intentions, Wantedness, and child survival in rural Northern Ghana. Stud Fam Plann 2016;47:252-63.

21 Binagwaho A, Farmer PE, Nsanzimana S, et al. Rwanda 20 years on investing in life. Lancet 2014;384:371-5.

22 Schwandt HM, Feinberg S, Akotiah A, et al. "Family planning in Rwanda is not seen as population control, but rather as a way to empower the people": examining Rwanda's success in family planning from the perspective of public and private stakeholders. Contracept Reprod Med 2018;3:18.
23 Abimpaye M, Kirk CM, lyer HS, et al. The impact of "Option B" on HIV transmission from mother to child in Rwanda: An interrupted time series analysis. PLoS One 2018;13:e0192910.

24 USAID/Rwanda. Gender analysis for Rwanda, 2014. Available: https://www.usaid.gov/sites/default/files/documents

25 Rwanda Biomedical Centre. National HIV and viral hepatitis annual report 2014/15, 2015.

26 Ministry of Health Rwanda, National Institute of Statictics of Rwanda I macro. Rwanda demographic health survey 2014-15.

27 Mugwaneza P, Umutoni NWS, Ruton $\mathrm{H}$, et al. Under-two child mortality according to maternal HIV status in Rwanda: assessing outcomes within the National PMTCT program. Pan Afr Med J 2011;9:37.

28 Ndirangu J, Newell M-L, Tanser F, et al. Decline in early life mortality in a high HIV prevalence rural area of South Africa: evidence of HIV prevention or treatment impact? AIDS 2010;24:593-602.

29 Ndirangu J, Newell M-L, Thorne C, et al. Treating HIV-infected mothers reduces under 5 years of age mortality rates to levels seen in children of HIV-uninfected mothers in rural South Africa. Antivir Ther 2011;17:81-90.

30 Andriano L, Monden CWS. The causal effect of maternal education on child mortality: evidence from a Quasi-Experiment in Malawi and Uganda. Demography 2019;56:1765-90.

31 Maniruzzaman M, Suri HS, Kumar N, et al. Risk factors of neonatal mortality and child mortality in Bangladesh. $J$ Glob Health 2018;8:10417.

32 Maïga A, Hounton S, Amouzou A, et al. Trends and patterns of modern contraceptive use and relationships with high-risk births and child mortality in Burkina Faso. Glob Health Action 2015;8:29736.

33 Chola L, McGee S, Tugendhaft A, et al. Scaling up family planning to reduce maternal and child mortality: the potential costs and benefits of modern contraceptive use in South Africa. PLoS One 2015;10:e0130077

34 Bado AR, Sathiya Susuman A. Women's education and health inequalities in Under-Five mortality in selected sub-Saharan African countries, 1990-2015. PLoS One 2016;11:e0159186.

35 Nsanzimana S, Remera E, Kanters S, et al. Life expectancy among HIV-positive patients in Rwanda: a retrospective observational cohort study. Lancet Glob Health 2015;3:e169-77. 